\title{
A surface protein-imprinted biosensor based on boronate affinity for the detection of anti-human immunoglobulin G
}

\author{
Zixuan $\mathrm{Liu}^{1} \cdot$ Zheng-Zhi Yin $^{2} \cdot$ Wenrong Cai ${ }^{1} \cdot$ Datong Wu ${ }^{1} \cdot$ Junyao $\mathrm{Li}^{1} \cdot$ Yong Kong $^{1}$
}

Received: 18 September 2021 / Accepted: 29 January 2022 / Published online: 15 February 2022

(c) The Author(s), under exclusive licence to Springer-Verlag GmbH Austria, part of Springer Nature 2022

\begin{abstract}
A surface protein-imprinted biosensor was constructed on a screen-printed carbon electrode (SPCE) for the detection of anti-human immunoglobulin G (anti-IgG). The SPCE was successively decorated with aminated graphene $\left(\mathrm{NH}_{2}-\mathrm{G}\right)$ and gold nanobipyramids (AuNBs) for signal amplification. Then 4-mercaptophenylboric acid (4-MPBA) was covalently anchored to the surface of AuNBs for capturing anti-IgG template through boronate affinity binding. The decorated SPCE was then deposited with an imprinting layer generated by the electropolymerization of pyrrole. After removal of the anti-IgG template by the dissociation of the boronate ester in an acidic solution, three-dimensional (3D) cavities complementary to the anti-IgG template were formed in the imprinting layer of polypyrrole (PPy). The molecularly imprinted polymers (MIP)based biosensor was used for the detection of anti-IgG, exhibiting a wide linear range from 0.05 to $100 \mathrm{ng} \mathrm{mL}^{-1}$ and a low limit of detection of $0.017 \mathrm{ng} \mathrm{mL}^{-1}(\mathrm{~S} / \mathrm{N}=3)$. In addition, the MIP-based anti-IgG biosensor also shows high selectivity, reproducibility and stability. Finally, the practicability of the fabricated anti-IgG biosensor was demonstrated by accurate determination of anti-IgG in serum sample.
\end{abstract}

Keywords Molecularly imprinted polymers $\cdot$ Surface imprinting $\cdot$ Boronate affinity $\cdot$ Gold nanobipyramids $\cdot$ Anti-IgG

\section{Introduction}

Antibodies are glycoproteins involved in the pathogenesis of autoimmune diseases, which play a critical role in immunopathology [1]. The past years have witnessed the detection of antibodies as an important approach for the diagnosis of several diseases such as HIV [2], dengue [3], Zika virus [4] and autoimmune diseases [5]. Particularly, due to the fast global spread of coronavirus disease (COVID-19) from the end of 2019, assay of immunoglobulin G (IgG) and immunoglobulin $\mathrm{M}(\mathrm{IgM})$ antibodies for evaluating the diagnostic accuracy is especially important for COVID-19 patients [6]. As a valuable alternative, electrochemical biosensors can

Zheng-Zhi Yin

yinzhengzhi@zjxu.edu.cn

Yong Kong

yzkongyong@cczu.edu.cn

1 Jiangsu Key Laboratory of Advanced Catalytic Materials and Technology, School of Petrochemical Engineering, Changzhou University, Changzhou 213,164, China

2 College of Biological, Chemical Sciences and Engineering, Jiaxing University, Jiaxing 314,001, China be regarded as a feasible strategy for the rapid, specific and sensitive detection of antibodies at the point-of-care [7].

It is usually difficult for the imprinting of biological macromolecules (e.g. proteins) due to their restricted mobility within the highly cross-linked polymer matrix [8]. Apart from this, imprinting under harsh conditions often leads to protein denaturation [9]. Compared with small organic molecules used as the templates in molecularly imprinting polymers (MIP), proteins possess complex surface binding sites, and therefore appropriate complementarities and polymerization procedures are especially essential for successful fabrication of MIP-based protein sensors [10]. Various imprinting strategies such as surface imprinting [11], epitope imprinting [12] and microcontact imprinting [13] have been proposed to solve these problems frequently encountered by proteins imprinting. Among the developed methods, surface imprinting is especially attractive owing to its high binding capacity, rapid mass transfer and efficient removal of template [14]. Recently, boronate affinity controllable-oriented imprinting has been utilized for surface imprinting since it can allow easy and efficient preparation of MIP specific to glycoproteins [15]. For example, Wang et al. reported that a glycoprotein template was covalently anchored onto the surface of a boronic acid-functionalized substrate 
through boronate affinity binding for the preparation of MIP [16]. The principle of boric acid affinity is that under the condition of $\mathrm{pH} 6 \sim 10$, boric acid can covalently interact with molecules containing $c i$-diol to form stable cycloesters, which will be dissociated at $\mathrm{pH}<3$, and this reversible binding makes boric acid an excellent affinity ligand for MIP [17]. Electropolymerization is a straightforward approach for the preparation of polymers used as the matrix of surface imprinting [18], since the thickness and the morphology of the electrodeposited polymer films can be controlled through electropolymerization conditions [19].

To enhance the sensitivity of MIP-based sensors, various nanomaterials such as gold nanoparticles (AuNPs), carbon nanotube (CNT) and graphene have been used for electrode modification [20]. Among them, graphene has received increasing attention in electrochemical biosensors due to its robust mechanical property as well as high conductivity and electron mobility [21]. In addition, graphene can also be coated with metal or metal oxide NPs for signal amplification [22]. As another kind of important nanomaterials, AuNPs exhibit high chemical stability and electron transfer capacity, excellent biocompatibility, which have been widely used in electrochemical bioanalysis. However, the commonly used AuNPs are spherical in shape, and little attention has been paid to the use of Au nanobipyramids (AuNBs) in biosensors [23]. Compared with spherical AuNPs, AuNBs might be a potential alternative to obtain higher sensitivity owing to their sharper tips [24]. In fact, the plasmonic responses and local field enhancement of noble metal NPs can be tuned through their shape and size [25], which can in turn influence the voltammetric signals of the noble metal NPs.

In this work, a novel surface protein-imprinted biosensor based on boronate affinity was proposed for the detection of anti-IgG. A screen-printed carbon electrode (SPCE) was successively decorated with aminated graphene $\left(\mathrm{NH}_{2}-\mathrm{G}\right)$ and AuNBs for signal amplification, which was further decorated with 4-mercaptophenylboric acid (4-MPBA) through Au-S bond. The anti-IgG template can be covalently anchored to the surface of 4-MPBA through the specific boronic acid-diol binding, and then the substrate was deposited with an imprinting layer generated by the electropolymerization of pyrrole. After removal of the template in an acidic solution, the MIP-based biosensor was obtained, which can be successfully applied in the sensitive and selective detection of anti-IgG by using $\left[\mathrm{Fe}(\mathrm{CN})_{6}\right]^{3-/ 4-}$ as the signal probe.

\section{Experimental}

\section{Reagents and apparatus}

Tetrachloroauric (III) acid trihydrate $\left(\mathrm{HAuCl}_{4} \cdot 3 \mathrm{H}_{2} \mathrm{O}\right)$, trisodium citrate dihydrate, ascorbic acid (AA), silver nitrate
$\left(\mathrm{AgNO}_{3}\right)$, hydrochloric acid $(\mathrm{HCl})$, cetyltrimethylammonium bromide (CTAB), sodium borohydride $\left(\mathrm{NaBH}_{4}\right)$, potassium chloride $(\mathrm{KCl})$, sodium chloride $(\mathrm{NaCl})$, calcium chloride $\left(\mathrm{CaCl}_{2}\right)$, sodium bicarbonate $\left(\mathrm{NaHCO}_{3}\right)$ and ethanol were purchased from Sinopharm Chemical Reagent Co., Ltd. (Shanghai, China). Aminated graphene $\left(\mathrm{NH}_{2}-\mathrm{G}\right)$, graphene oxide (GO), $-\mathrm{COOH}$ functionalized graphene $(\mathrm{COOH}-\mathrm{G}),-\mathrm{OH}$ functionalized graphene $(\mathrm{OH}-\mathrm{G})$ and nitrogen-doped graphene $(\mathrm{N}-\mathrm{G})$ were obtained from Chengdu Organic Chemicals Co., Ltd., Chinese Academy of Sciences (Chengdu, China). 4-Mercaptophenylboric acid (4-MPBA), bovine serum albumin (BSA), glucose (Glu), L-tyrosine (L-Tyr) and hemoglobin (HGB) were purchased from Aladdin Chemistry Co., Ltd. (Shanghai, China). Pyrrole was received from Shanghai Macklin Biochemical Technology Co., Ltd. (Shanghai, China). Goat anti-human IgG (anti-IgG) and rabbit anti-IgG immune serum sample were obtained from Beijing Solarbio Science and Technology Co., Ltd. (Beijing, China). Screen-printed electrodes with working $(d=5 \mathrm{~mm})$ and counter electrode of carbon and a reference electrode of silver were purchased from NEOPRO Biotechnologies Co. Ltd. (Weihai, China). All aqueous solutions were prepared with ultrapure water (18.2 $\mathrm{M} \Omega \mathrm{cm}$, Millipore).

Transmission electron microscopy (TEM) and scanning electron microscopy (SEM) characterizations of different samples were conducted with a JEM 2100 transmission electron microscope (JEOL, Japan) and a Supra55 fieldemission scanning electron microscope (Zeiss, Germany), respectively. The visible absorption spectrum of AuNBs was recorded by using a U-3900 UV-Vis spectrophotometer (Hitachi, Japan). All electrochemical experiments including cyclic voltammetry (CV), electrochemical impedance spectroscopy (EIS) and differential pulse voltammetry (DPV) were carried out on a CHI 660E electrochemical workstation (Shanghai Chenhua Instruments Co., Ltd., China).

\section{Synthesis of AuNBs}

AuNBs were synthesized by the seed-mediated growth method previously reported [26], and the detailed procedures were described in Supporting Information. For control experiments, Au nanoparticles (AuNPs) and Au nanorods (AuNRs) were also synthesized according to the previous literatures [27, 28], respectively.

\section{Modification of screen-printed carbon electrode (SPCE) and immobilization of anti-IgG}

Five microliters of the $\mathrm{NH}_{2}-\mathrm{G}$ dispersion $\left(1.0 \mathrm{mg} \mathrm{mL}^{-1}\right)$ was dropped onto the SPCE surface and allowed to dry in ambient air. Next, $5.0 \mu \mathrm{L}$ of the AuNB suspension $\left(0.4 \mathrm{mg} \mathrm{mL}^{-1}\right)$ was gently dropped onto the $\mathrm{NH}_{2}-\mathrm{G} / \mathrm{SPCE}$ surface and 
dried in ambient air. After that, $5.0 \mu \mathrm{L}$ of ethanol containing $1.0 \mathrm{mM}$ 4-MPBA was dropped on the AuNBs/ $\mathrm{NH}_{2}-\mathrm{G} /$ SPCE surface and dried in ambient air, and 4-MPBA was self-assembled on the electrode surface through $\mathrm{Au}-\mathrm{S}$ bond. After every step of modification, the unbound modifier was washed off by water. Finally, $5.0 \mu \mathrm{L}$ of $0.1 \mathrm{M}$ phosphate buffer saline (PBS, $\mathrm{pH}=7.4$ ) containing $100 \mu \mathrm{g} \mathrm{mL}^{-1}$ antiIgG was dropped onto the MPBA/AuNBs/ $/ \mathrm{NH}_{2}-\mathrm{G} / \mathrm{SPCE}$ surface. After incubation for $12 \mathrm{~h}$, the unbound anti-IgG was washed successively by $0.1 \mathrm{M}$ PBS of $\mathrm{pH} 7.4$ and water, and the resultant electrode was denoted as Anti-IgG/MPBA/ AuNBs/NH ${ }_{2}-\mathrm{G} / \mathrm{SPCE}$.

\section{Fabrication of MIP biosensor}

One hundred microliters of $0.01 \mathrm{M}$ PBS containing $0.1 \mathrm{M}$ pyrrole was dropped onto the surface of the Anti-IgG/ MPBA/AuNBs/ $\mathrm{NH}_{2}-\mathrm{G} / \mathrm{SPCE}$, and the electropolymerization of pyrrole was carried out by $\mathrm{CV}$ in the potential range between -0.3 and $0.8 \mathrm{~V}$ at a scan rate of $50 \mathrm{mV} \mathrm{s}^{-1}$ for 10 cycles. After that, $100 \mu \mathrm{L}$ of $0.2 \mathrm{M} \mathrm{HCl}$ was dropped onto the surface and kept for $25 \mathrm{~min}$ to remove the entrapped anti-IgG template. After washing with $0.1 \mathrm{M}$ PBS, the MIP biosensor denoted as MIP/MPBA/AuNBs/ $/ \mathrm{NH}_{2}-\mathrm{G} / \mathrm{SPCE}$ was obtained. For control experiments, the non-imprinted biosensor was also fabricated by the same procedure in the absence of anti-IgG, which was denoted as NIP/MPBA/ AuNBs/NH ${ }_{2}-\mathrm{G} / \mathrm{SPCE}$.

\section{Detection of anti-IgG by MIP biosensor}

The as-fabricated MIP biosensor was incubated with different concentrations of anti-IgG in $5.0 \mu \mathrm{L} 0.1 \mathrm{M}$ PBS at
$4{ }^{\circ} \mathrm{C}$ for $6 \mathrm{~h}$, which was then washed with $0.1 \mathrm{M}$ PBS to remove the free anti-IgG. Next, the rebound anti-IgG to the biosensor was detected by DPV in $0.1 \mathrm{M}$ PBS containing $0.1 \mathrm{M} \mathrm{KCl}$ and $5 \mathrm{mM}\left[\mathrm{Fe}(\mathrm{CN})_{6}\right]^{3-/ 4-}$ used as the signal probe. Schematic illustration showing the fabrication of the MIP biosensor and the detection of anti-IgG is presented in Fig. 1.

\section{Detection of anti-IgG in serum sample}

To demonstrate the practicality of the proposed MIP biosensor, anti-IgG in serum sample is detected with the MIP biosensor by standard addition method. Purified rabbit antiIgG immune serum $(50 \mu \mathrm{L})$ was diluted with $5 \mathrm{~mL}$ PBS of $\mathrm{pH} 7.4$, and then different concentrations of anti-IgG (ranging from $0.5 \mathrm{ng} \mathrm{mL}^{-1}$ to $2.0 \mathrm{ng} \mathrm{mL}^{-1}$ ) were added into the diluted sample, respectively, which were detected by DPV in the potential range from -0.2 to $0.8 \mathrm{~V}$.

\section{Results and discussion}

\section{Visible spectra of AuNBs, AuNPs and AuNRs}

First, AuNBs, AuNPs and AuNRs are characterized by visible spectra (Fig. S1 in Supporting Information). Two distinct bands appear at around 535 and $725 \mathrm{~nm}$, respectively, on the visible absorption spectrum of AuNBs. The former could be attributed to the combination of interband transitions and transverse plasmon resonances from the bases of AuNBs and the byproduct spherical particles, while the latter corresponds to the longitudinal plasmon resonance of AuNBs [29]. The visible spectrum of AuNBs clearly indicates that
Fig. 1 Schematic illustration showing the fabrication of the MIP biosensor and the detection of anti-IgG

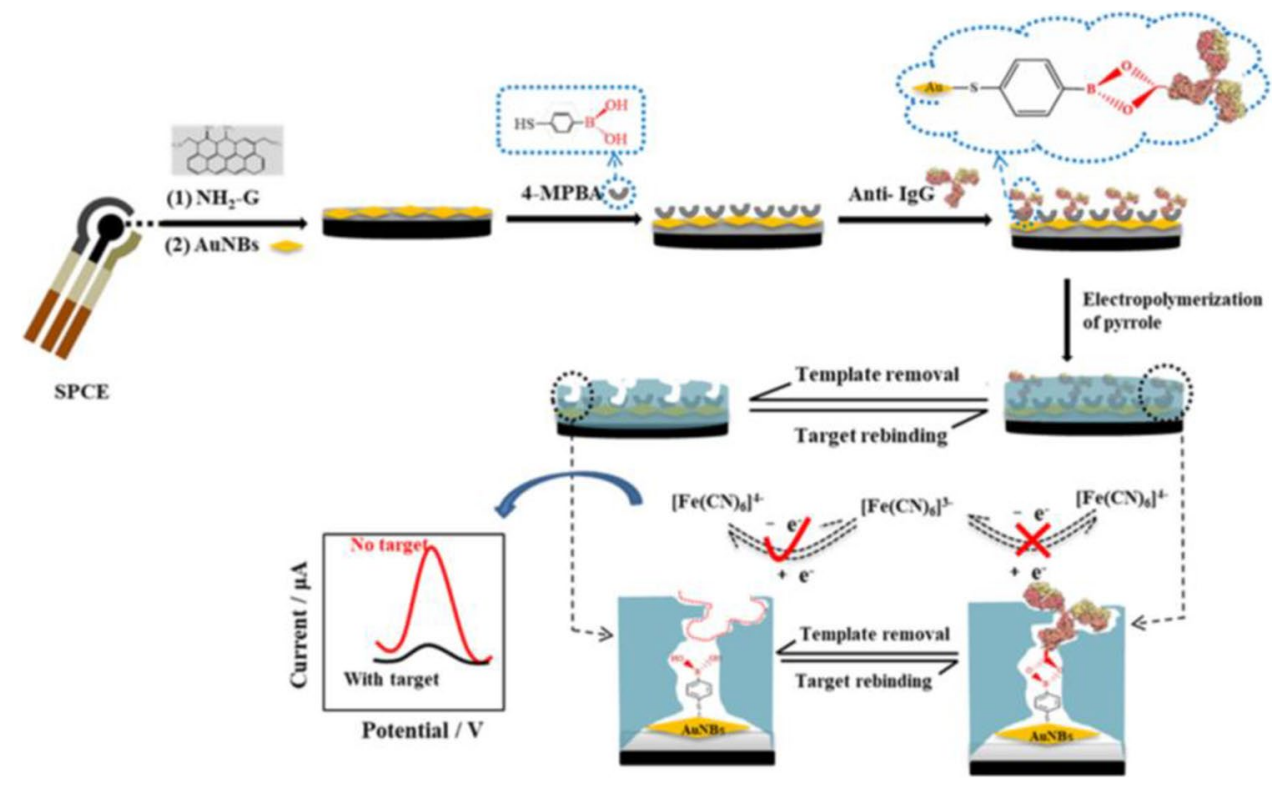


the AuNBs can be successfully synthesized by the seedmediated growth method.

The absorption band of AuNPs (520 nm) is near to the transverse plasmon resonance of AuNBs (535 nm), suggesting that the size of AuNPs is similar to the transverse size of AuNBs. The absorption band of AuNRs $(800 \mathrm{~nm})$ is greatly longer than the longitudinal plasmon resonance of AuNBs (725 nm), suggesting that the length of AuNRs is greater than the longitudinal size of AuNBs. These assumptions can be further confirmed by the TEM images of AuNPs and AuNRs (Fig. S2 in Supporting Information).

\section{TEM and SEM images of different samples}

To reveal the successful integration of $\mathrm{NH}_{2}-\mathrm{G}$ and AuNBs, the TEM images of $\mathrm{NH}_{2}-\mathrm{G}$, AuNBs and AuNBs/ $/ \mathrm{NH}_{2}-\mathrm{G}$ are shown in Fig. 2. The $\mathrm{NH}_{2}-\mathrm{G}$ exhibits a sheet-like morphology with abundant wrinkles over the layers (Fig. 2A), agreeing well with the previous report [30]. Typical bipyramids can be observed for the AuNBs (Fig. 2B), and the average size of the AuNBs is determined to be $43.48 \mathrm{~nm}$ by the software Nano Measurer. As can be seen from Fig. 2C, the AuNBs can be well distributed on the $\mathrm{NH}_{2}-\mathrm{G}$ nanosheets without aggregation, suggesting that the $\mathrm{NH}_{2}-\mathrm{G}$ might be an excellent support for the loading of AuNBs.

The SEM images of $\mathrm{NH}_{2}-\mathrm{G}$, AuNBs/ $\mathrm{NH}_{2}-\mathrm{G}$ and MIP/ MPBA/AuNBs $/ \mathrm{NH}_{2}-\mathrm{G}$ before and after template removal are shown in Fig. 3. A multilayered structure is observed for the $\mathrm{NH}_{2}-\mathrm{G}$, which is accompanied by extensive stacking and folding (Fig. 3A). The small AuNBs are uniformly anchored onto the $\mathrm{NH}_{2}-\mathrm{G}$ nanosheets (Fig. 3B). After further electropolymerization of pyrrole, a compact polypyrrole (PPy) film can be observed on the surface (Fig. 3C), suggesting that electrodeposition of PPy could be a feasible strategy for the formation of the imprinting layer. After the removal of the anti-IgG template in the acidic solution $(0.2 \mathrm{M} \mathrm{HCl})$, the MIP/MPBA/AuNBs/ $\mathrm{NH}_{2}-\mathrm{G}$ exhibits a micro-porous structure (Fig. 3D), which is especially favorable for the further accommodation of the anti-IgG target.

\section{Comparison of different graphene derivatives}

Several graphene derivates including GO, $\mathrm{COOH}-\mathrm{G}$, $\mathrm{OH}-\mathrm{G}, \mathrm{N}-\mathrm{G}$ and $\mathrm{NH}_{2}-\mathrm{G}$ are compared. The results show that among all these modified electrodes, the AuNBs/ $\mathrm{NH}_{2}$-G/SPCE displays the highest peak currents on the cyclic voltammograms (Fig. S3 in Supporting Information). $\mathrm{N}$ atom has lone pair electrons, which can form stable coordination bonds with Au atom. Compared with other groups such as $-\mathrm{COOH},-\mathrm{NH}_{2}$ has smaller steric hindrance and can be easier to coordinate with Au. The AuNBs/ $\mathrm{NH}_{2}-\mathrm{G} / \mathrm{SPCE}$ exhibits the highest peak currents because more amount of AuNBs can be anchored to the surface of the $\mathrm{NH}_{2}$ - G/SPCE. Therefore, $\mathrm{NH}_{2}-\mathrm{G}$ is chosen for the construction of the anti-IgG biosensor in this work.
Fig. 2 TEM images of $\mathrm{NH}_{2}-\mathrm{G}$ (A), AuNBs (B) and AuNBs/ $\mathrm{NH}_{2}-\mathrm{G}(\mathbf{C})$

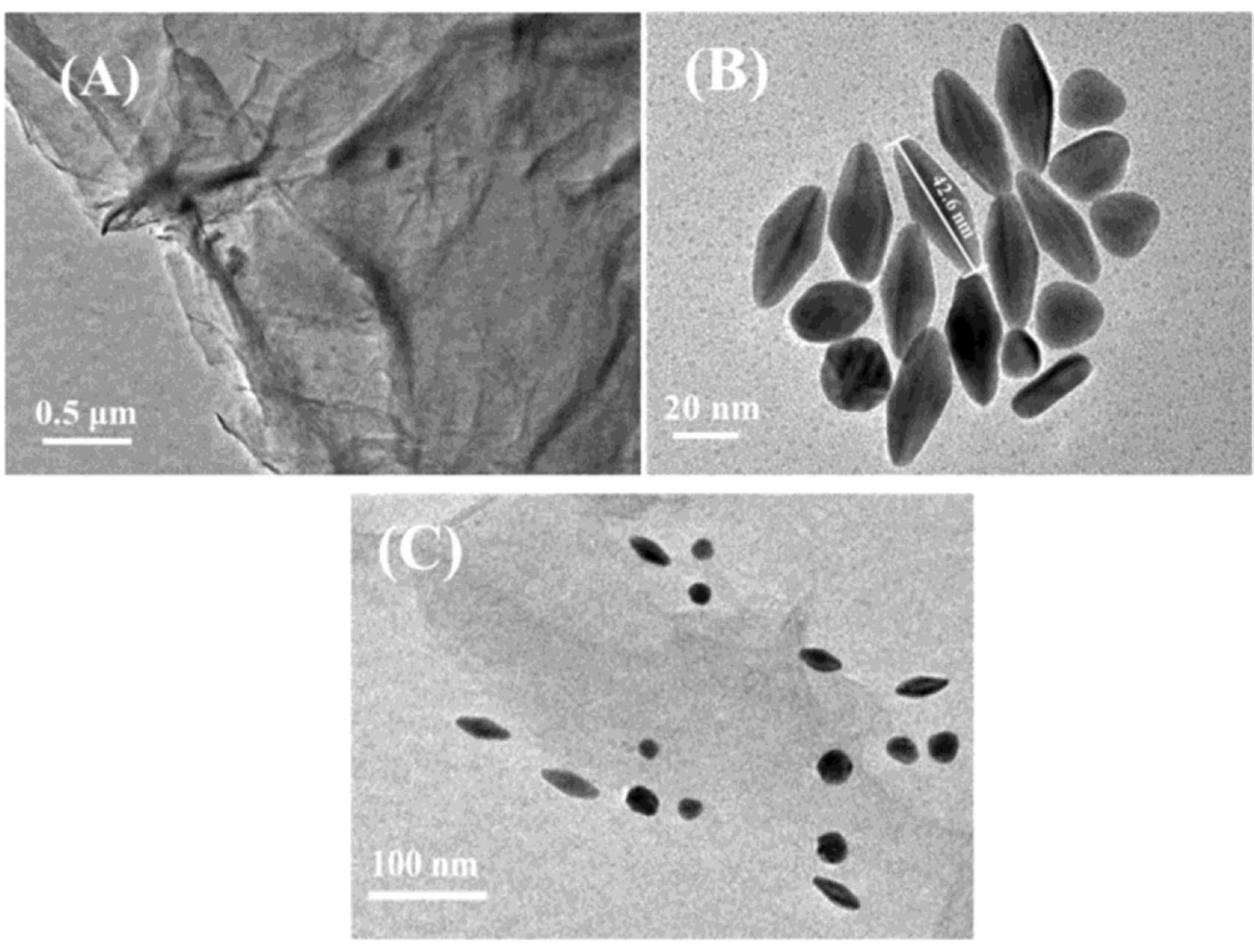


Fig. 3 SEM images of $\mathrm{NH}_{2}-\mathrm{G}$ (A), AuNBs/ $\mathrm{NH}_{2}-\mathrm{G}$ (B), MIP/ MPBA/AuNBs/ $/ \mathrm{NH}_{2}-\mathrm{G}$ before (C) and after (D) template removal

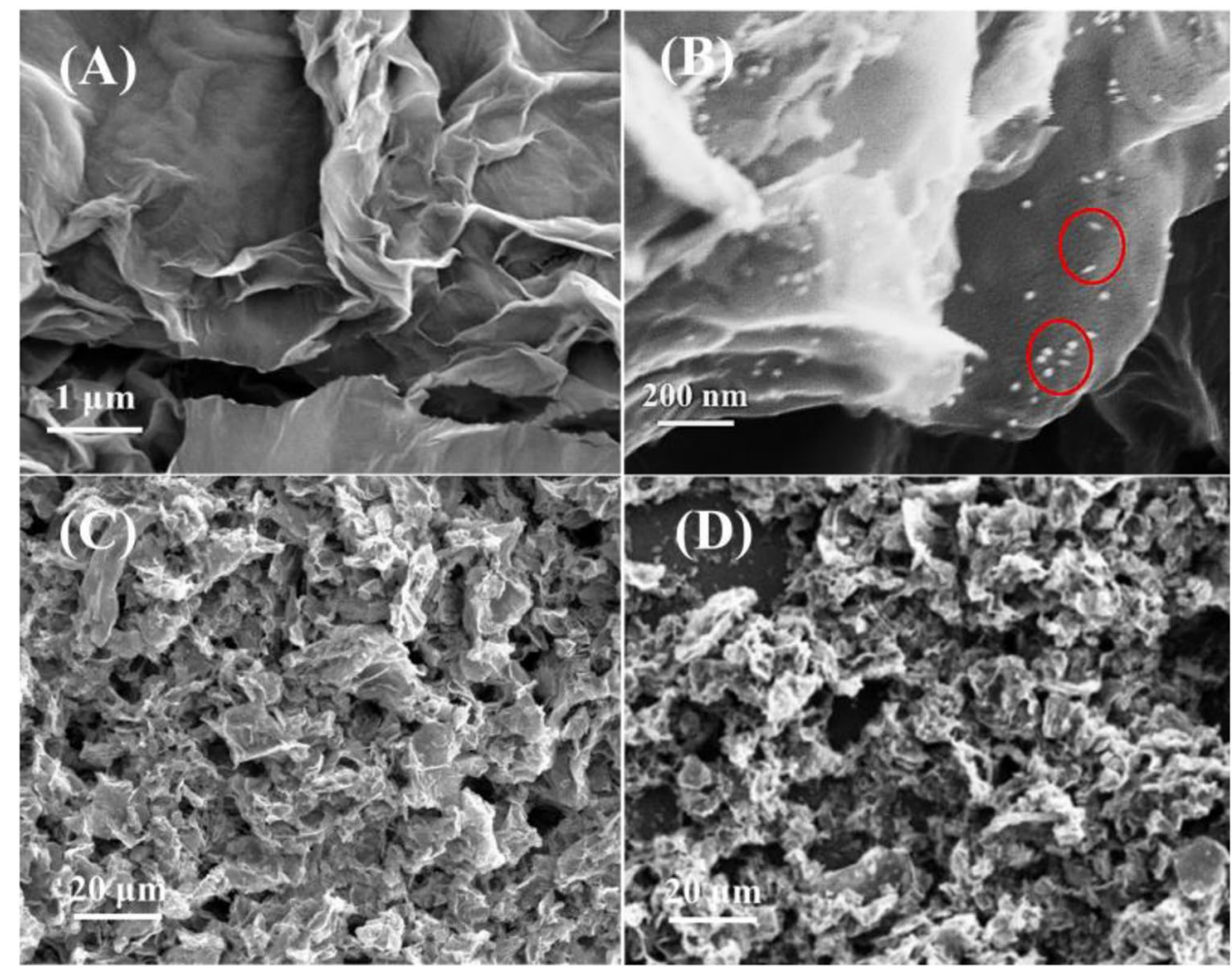

\section{Comparison of AuNPs, AuNRs and AuNBs}

The cyclic voltammograms of bare SPCE and $\mathrm{NH}_{2}-\mathrm{G} / \mathrm{SPCE}$ respectively modified with AuNPs, AuNRs and AuNBs are studied (Fig. S4 in Supporting Information). Among the four tested electrodes, AuNBs exhibit the highest electroactivity since the areas under the cyclic voltammograms of AuNBs/ $/ \mathrm{NH}_{2}-\mathrm{G} / \mathrm{SPCE}$ are much larger than those of another two electrodes. The higher electroactivity of AuNBs might be attributed to their sharper tips, which could result in enhanced plasmonic responses and local field. As previously reported [24, 25], nanoparticles with sharp tips (such as bipyramids and nanotriangles) are particularly sensitive to the change of refractive index and the enhancement of strong magnetic field. In addition, gold nanoparticles with special morphology have higher dielectric displacement among the existing nanoparticles, which can accelerate the electron transfer at the interface, and thus we believe that these unique characteristics of AuNBs may be the reason for their enhanced voltammetric signals. Therefore, AuNBs but not AuNPs and AuNRs are used in this work for electrode modification.

\section{Electrochemical characterizations during the step-by-step modification}

The step-by-step modification of the SPCE is characterized by $\mathrm{CV}$ and EIS, respectively. Figure $4 \mathrm{~A}$ shows the cyclic voltammograms of different electrodes in $0.1 \mathrm{M}$ PBS $(\mathrm{pH}=7.4)$ containing $0.1 \mathrm{M} \mathrm{KCl}$ and $5 \mathrm{mM}\left[\mathrm{Fe}(\mathrm{CN})_{6}\right]^{3-/ 4-}$. A pair of well-defined redox peaks is observed on the bare SPCE (curve a), which is due to the redox reaction between $\left[\mathrm{Fe}(\mathrm{CN})_{6}\right]^{4-}$ and $\left[\mathrm{Fe}(\mathrm{CN})_{6}\right]^{3-}$. The peak currents increase remarkably with the successive modification with $\mathrm{NH}_{2}-\mathrm{G}$ (curve b) and AuNBs (curve c), indicating that signal amplification may be achieved by $\mathrm{NH}_{2}-\mathrm{G}$ and AuNBs. Note that after the introduction of electroinactive 4-MPBA through the formation of $\mathrm{Au}-\mathrm{S}$ bond, the peak currents decrease greatly and are even lower than those at bare SPCE (curve d). The peak currents decrease further after the immobilization of the anti-IgG template through boronate affinity binding (curve e), which might be ascribed to the low conductivity of anti-IgG and the consequent inhibited charge transfer at the electrode/solution interfaces.

Figure 4B shows the Nyquist plots of different electrodes in the same electrolyte (frequency range: $10^{5} \sim 0.01 \mathrm{~Hz}$; open circuit potential: $0.28 \mathrm{~V}$ ). The diameter of the suppressed semicircle at high frequency is closely related to the charge transfer resistance $\left(R_{\mathrm{ct}}\right)$ [31], and smaller diameter represents lower $R_{\mathrm{ct}}$. As can be seen, the $R_{\mathrm{ct}}$ values of these electrodes are arranged in such an order: AuNBs/ $\mathrm{NH}_{2}-\mathrm{G} / \mathrm{SPCE}$ $(186.8 \Omega)<\mathrm{NH}_{2}-\mathrm{G} / \mathrm{SPCE}(403.9 \Omega)<$ bare SPCE $(548.4$ $\Omega)<$ MPBA/AuNBs/NH ${ }_{2}$ G/SPCE $(11,96.2 \Omega)<$ Anti-IgG/ MPBA/AuNBs/ $\mathrm{NH}_{2}$-G/SPCE (5441.6 $\Omega$ ), agreeing well with the results shown in Fig. 4A. Due to the good electron transport capability of $\mathrm{NH}_{2}-\mathrm{G}$ and AuNBs, the $R_{\mathrm{ct}}$ value of 


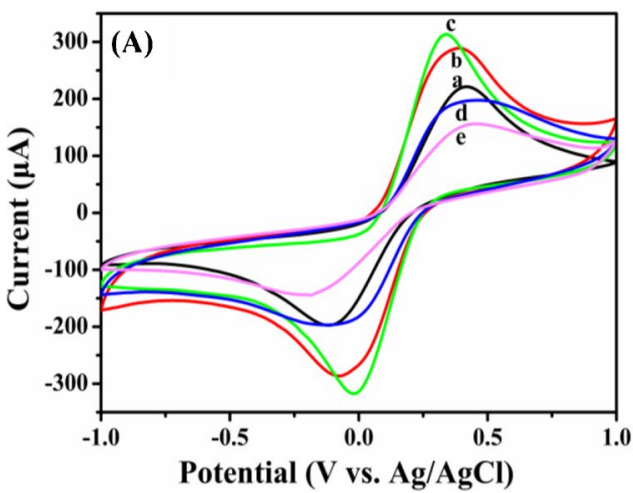

Fig. 4 Cyclic voltammograms (A) and Nyquist plots (B) of bare SPCE (a), $\mathrm{NH}_{2}-\mathrm{G} / \mathrm{SPCE}$ (b), AuNBs/NH $\mathrm{N}_{2}-\mathrm{G} / \mathrm{SPCE}$ (c), MPBA/ AuNBs/NH $/ \mathrm{NH}_{2}-\mathrm{SPCE}$ (d) and Anti-IgG/MPBA/AuNBs/NH ${ }_{2}-\mathrm{G} /$ SPCE (e) in $0.1 \mathrm{M}$ PBS $(\mathrm{pH}=7.4)$ containing $0.1 \mathrm{M} \mathrm{KCl}$ and $5 \mathrm{mM}$ $\left[\mathrm{Fe}(\mathrm{CN})_{6}\right]^{3-/ 4-}$. The equivalent circuit shown in the inset of $(\mathbf{B})$ was

the bare SPCE decreases significantly from $548.4 \Omega$ to 403.9 and $186.8 \Omega$ after its respective modification with $\mathrm{NH}_{2}-\mathrm{G}$ and AuNBs/ $\mathrm{NH}_{2}$-G. After 4-MPBA and anti-IgG are further introduced to the surface of the AuNBs/ $\mathrm{NH}_{2}-\mathrm{G} / \mathrm{SPCE}$, the $R_{\mathrm{ct}}$ values increase to 1196.2 and $5441.6 \Omega$, respectively, and the remarkably increased $R_{\mathrm{ct}}$ values might be ascribed to the poor conductivity of 4-MPBA and anti-IgG.

\section{Electrodeposition of PPy as the imprinting layer}

The cyclic voltammograms obtained during the electrodeposition of PPy on the surface of Anti-IgG/MPBA/AuNBs/ $\mathrm{NH}_{2}$-G/SPCE are studied (Fig. S5A in Supporting Information). During the process, the anti-IgG molecules can be entrapped into the polymeric structure of PPy through molecular interactions probably between the hydroxyl groups of anti-IgG and the amine groups of PPy, and the interactions might contribute largely to the formation of the imprinted cavities [32]. Due to the increase in the thickness of the PPy film, the currents decrease with increasing cycling number. The cyclic voltammograms during the electrodeposition of PPy on the surface of MPBA/AuNBs/ $\mathrm{NH}_{2}$-G/SPCE are also presented (Fig. S5B in Supporting Information). Note that the currents are greatly higher than those in the presence of anti-IgG although they still decrease as the number of cycles increases, demonstrating that the anti-IgG molecule is not electroactive.

\section{Removal of anti-IgG template}

Successful removal of the anti-IgG template can be confirmed by CV and EIS, respectively. The cyclic voltammograms of the MIP biosensor at different stages are shown in Fig. 5A. Since anti-IgG is not electroactive, the cyclic voltammograms exhibit low currents before the removal of

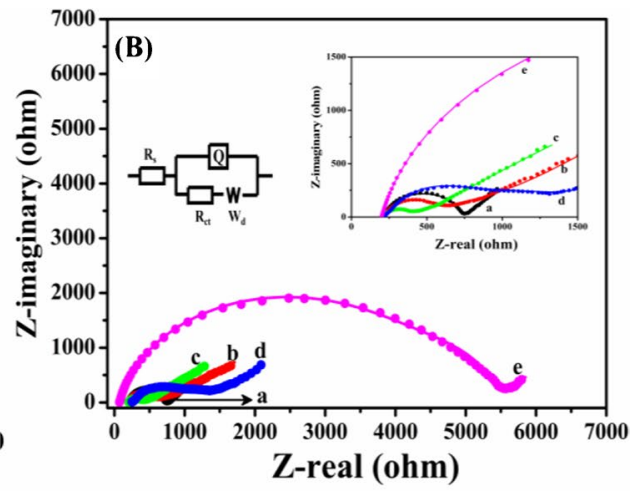

simulated by ZSimpWin software, where $R_{\mathrm{s}}$ represents the ohmic resistance of electrolyte and the internal resistance of electrode, $R_{\mathrm{ct}}$ represents the charge transfer resistance, $W_{\mathrm{d}}$ represents the Warburg resistance and $Q$ represents the constant phase element

anti-IgG (curve a). After the treatment with $0.2 \mathrm{M} \mathrm{HCl}$, the currents are significantly enhanced (curve $b$ ), which can be ascribed to the fact that the boronate ester linkage between 4-MPBA and the cis-diol groups of anti-IgG is dissociated in the acidic solution (Fig. S6 in Supporting Information), resulting in the removal of anti-IgG and consequently facilitated charge transfer. Note that the currents decrease again after the MIP biosensor is incubated in 0.1 M PBS containing $100 \mu \mathrm{g} \mathrm{mL}^{-1}$ anti-IgG (curve c), suggesting the rebinding of anti-IgG into the imprinted cavities through the re-formation of boronate ester with 4-MPBA. This phenomenon also demonstrates that the boronate affinity binding between 4-MPBA and anti-IgG is reversible. The EIS results agree well with the results of CV (Fig. 5B). For comparison, the cyclic voltammograms and the Nyquist plots of the NIP biosensor at different stages are also presented in Fig. 5C, D, respectively. Both the cyclic voltammograms and the Nyquist plots exhibit little differences before and after the treatment with $\mathrm{HCl}$. After the rebinding of anti-IgG, the cyclic voltammograms and the Nyquist plots still remain basically unchanged.

\section{Electrochemical kinetics of the MIP biosensor}

Next, the electrochemical kinetics of the MIP biosensor is investigated (Fig. S7 in Supporting Information). It shows that both the anodic peak currents $\left(I_{\mathrm{pa}}\right)$ and the cathodic peak currents $\left(I_{\mathrm{pc}}\right)$ increase linearly with the square root of the scan rate $\left(v^{1 / 2}\right)$, and the linear regression equations can be described as follows: $I_{\mathrm{pa}}=16.46 v^{1 / 2}+36.26\left(R^{2}=0.9998\right)$; $I_{\mathrm{pc}}=-14.17 v^{1 / 2}-45.17\left(R^{2}=0.9959\right)$. Obviously, the electrode process of the MIP biosensor is a typical diffusioncontrolled reaction.

The standard heterogeneous electron transfer rate constant $\left(k^{0}\right)$ is calculated to be $1.26 \times 10^{-5} \mathrm{~cm} \mathrm{~s}^{-1}$ from the 
Fig. 5 Cyclic voltammograms $(\mathbf{A}, \mathbf{C})$ and Nyquist plots $(\mathbf{B}$, D) of MIP biosensor $(\mathbf{A}, \mathbf{B})$ and NIP biosensor $(\mathbf{C}, \mathbf{D})$ in $0.1 \mathrm{M}$ PBS ( $\mathrm{pH}=7.4$ ) containing $0.1 \mathrm{M} \mathrm{KCl}$ and $5 \mathrm{mM}$ $\left[\mathrm{Fe}(\mathrm{CN})_{6}\right]^{3-/ 4-}$. (a) Before treatment with $0.2 \mathrm{HCl}$. (b) After treatment with $0.2 \mathrm{HCl}$. (c) After anti-IgG rebinding
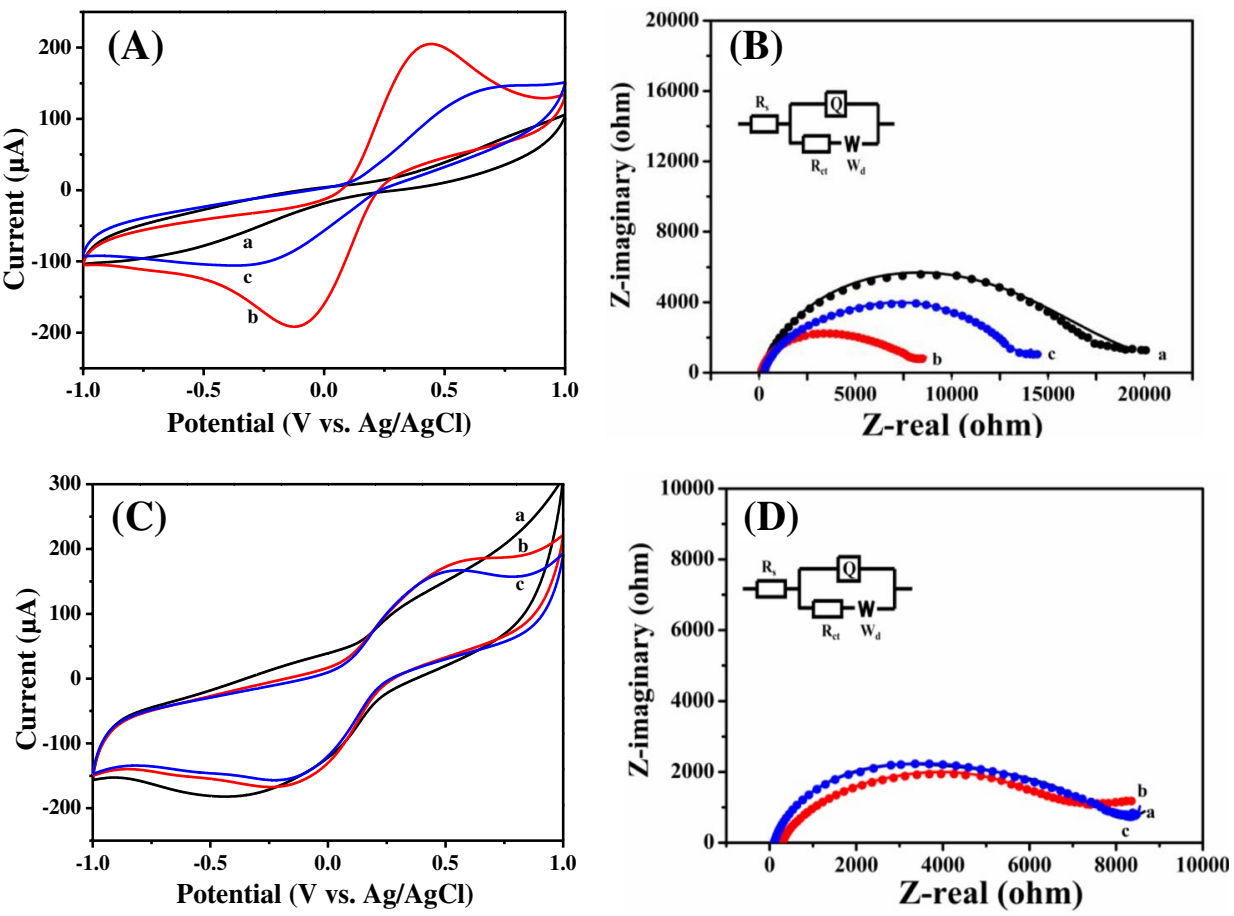

peak potential separation $\left(\Delta E_{\mathrm{p}}\right)$ according to the following equation [33]:

$k^{0}=2.18\left[\frac{\alpha D n F v}{R T}\right]^{1 / 2} \exp \left[\frac{-\alpha^{2} n F\left(E_{p a}-E_{p c}\right)}{R T}\right]$

where $\alpha$ is the charge transfer coefficient $(0.5), n$ is the electro transfer number (1.0), $D$ is the diffusion coefficient of $5 \mathrm{mM}\left[\mathrm{Fe}(\mathrm{CN})_{6}\right]^{3-/ 4-}\left(7.6 \times 10^{-6} \mathrm{~cm}^{2} \mathrm{~s}^{-1}\right), F$ is Faraday constant $\left(96,485 \mathrm{C} \mathrm{mol}^{-1}\right), \nu$ is scan rate $\left(0.1 \mathrm{~V} \mathrm{~s}^{-1}\right), R$ is the universal gas constant $\left(8.314 \mathrm{~J} \mathrm{~K}^{-1} \mathrm{~mol}^{-1}\right), T$ is temperature $(298.15 \mathrm{~K}), E_{p a}$ and $E_{p c}$ are the oxidation and reduction peak potential, respectively.

\section{Detection of anti-IgG}

After the incubation with anti-IgG of different concentrations for $6 \mathrm{~h}$, the differential pulse voltammograms of the MIP biosensor in $0.1 \mathrm{M}$ PBS $(\mathrm{pH}=7.4)$ containing $0.1 \mathrm{M}$ $\mathrm{KCl}$ and $5 \mathrm{mM}\left[\mathrm{Fe}(\mathrm{CN})_{6}\right]^{3-/ 4-}$ are shown in Fig. 6A. Due to the rebinding of anti-IgG into the imprinted cavities in the MIP biosensor, the $I_{\mathrm{pa}}$ decreases gradually with increasing concentration of anti-IgG. The calibration plot shows a good linear relationship between $I_{\mathrm{pa}}$ and the logarithm value of the anti-IgG concentration in a wide range from 0.05 to $100 \mathrm{ng} \mathrm{mL}^{-1}$ (Fig. 6B), and the linear regression equation can be expressed as: $I_{\mathrm{pa}}(\mu \mathrm{A})=-3.666 \lg C$ $\left(\mathrm{ng} \mathrm{mL}{ }^{-1}\right)+30.40\left(R^{2}=0.9940\right)$. The limit of detection (LOD) is calculated to be $0.017 \mathrm{ng} \mathrm{mL}^{-1}$ based on the signal-to-noise ratio of $3(\mathrm{~S} / \mathrm{N}=3)$. For comparison, the NIP biosensor is also used for the detection of anti-IgG. Even incubation with anti-IgG of a high concentration (100 $\mathrm{ng} \mathrm{mL} \mathrm{mL}^{-1}$ ), the $I_{\mathrm{pa}}$ varies little compared with the one before incubation (Fig. 6C). This comparison clearly indicates that the developed MIP biosensor can be used for the detection of anti-IgG. In fact, the developed MIP biosensor is also superior to the sensors previously reported when used for the detection of anti-IgG (Table S1 in Supporting Information). It shows that the developed MIP biosensor displays a wider linear range and a lower LOD than the previous anti-IgG sensors, indicating that our MIP biosensor might be more suitable for the accurate detection of anti-IgG.

\section{Optimization of parameters}

\section{Concentration of 4-MPBA}

Since 4-MPBA plays a crucial role in the immobilization of anti-IgG through boronate affinity binding, the amount of 4-MPBA anchored to the surface of AuNBs should be considered. As shown in Fig. 7A, the peak currents on the cyclic voltammograms of MPBA/ AuNBs/NH ${ }_{2}-\mathrm{G} / \mathrm{SPCE}$ first decrease with increasing 4-MPBA concentration till $1.0 \mathrm{mM}$ and then remain almost unchanged at higher concentrations, suggesting that the anchoring of 4-MPBA to the AuNBs surface is saturated at $1.0 \mathrm{mM}$. 
Fig. 6 (A) Differential pulse voltammograms of the MIP biosensor in 0.1 M PBS ( $\mathrm{pH}=7.4)$ containing $0.1 \mathrm{M} \mathrm{KCl}$ and $5 \mathrm{mM}\left[\mathrm{Fe}(\mathrm{CN})_{6}\right]^{3-/ 4-}$ before (a) and after incubation with anti-IgG of 0.05 (b), 0.1 (c), 0.5 (d), $1.0(\mathrm{e}), 10$ (f), 50 (g) and 100 (h) ng mL ${ }^{-1}$ for 6 h. (B) Calibration plot of anodic peak currents versus the logarithm value of anti-IgG concentration. (C) Differential pulse voltammograms of the NIP biosensor before (a) and after (b) incubation with anti-IgG of $100 \mathrm{ng} \mathrm{mL}{ }^{-1}$ for $6 \mathrm{~h}$
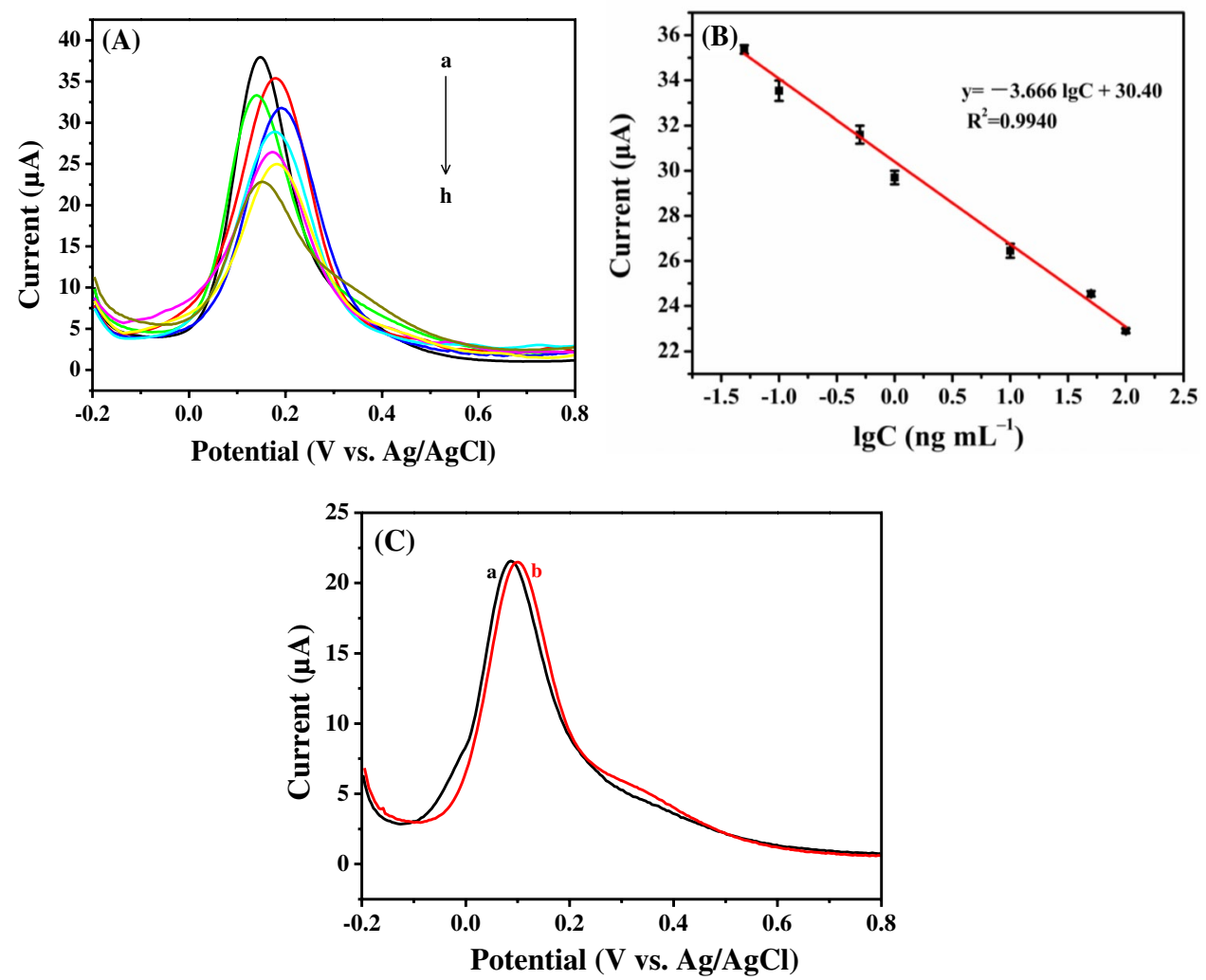

Fig. 7 Influence of 4-MPBA concentration (A), cycle number for PPy electrodeposition (B), elution time (C) and incubation time (D) on the performance of the MIP biosensor
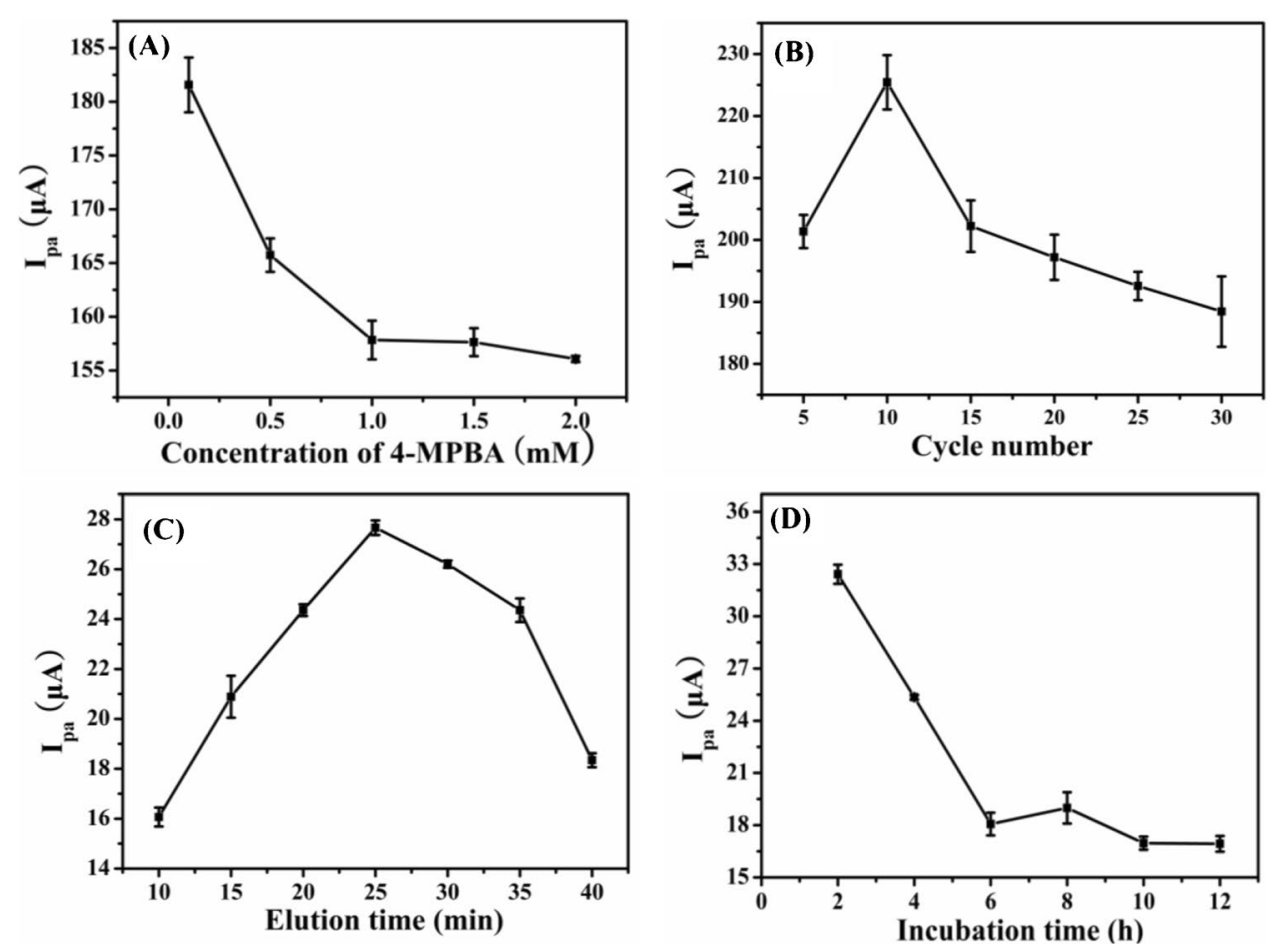

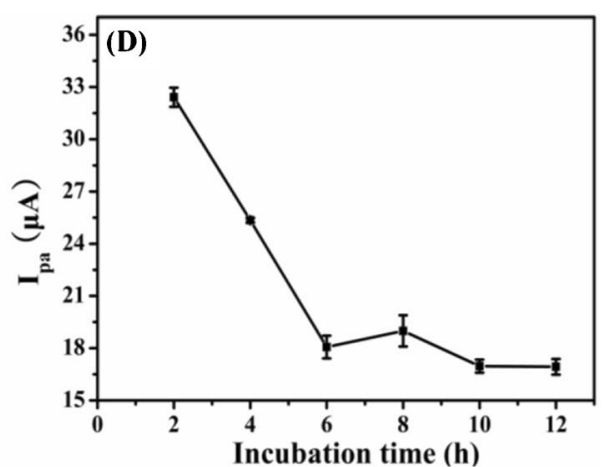

\section{Cycle number and scan rate for the electrodeposition of PPy}

The imprinting layer depends closely on the thickness of the PPy film, which can be adjusted by controlling the cycle number during the electrodeposition. The highest peak currents on the cyclic voltammograms of the MIP biosensor are observed when the electrodeposition of PPy is carried out for 10 cycles (Fig. 7B). At less cycle number, the MIP biosensor exhibits less sensitivity, probably due to less 
imprinted cavities in the MIP film; on the other hand, more cycles would lead to the formation of excessive thickness of film with less accessible imprinted sites [34].

The influence of scan rate for the electrodeposition of polypyrrole on the performance of the MIP biosensor is also studied (Fig. S8 in Supporting Information), and the highest peak currents are observed when PPy is deposited by $\mathrm{CV}$ at the scan rate of $50 \mathrm{mV} \mathrm{s}^{-1}$. Lower scan rates lead to less imprinting cavities in the MIP film, while higher scan rates result in thicker MIP film and difficult elution of the anti-IgG template.

\section{Elution time with $\mathrm{HCl}$}

In this work, the anti-IgG template is eluted with $0.2 \mathrm{M} \mathrm{HCl}$, and thus the elution time is also optimized. As shown in Fig. 7C, the peak currents on the differential pulse voltammograms of the MIP biosensor first increase with the elution time up to $25 \mathrm{~min}$ and then decrease with further increase in elution time. It might be ascribed to the nonspecific absorption of anti-IgG caused by longer elution time and the consequent incomplete removal of the anti-IgG template.

\section{Incubation time}

Figure 7D shows the influence of incubation time on the peak currents on the differential pulse voltammograms of the MIP biosensor. Due to the rebinding of anti-IgG into the imprinted cavities, the peak currents decrease gradually with increasing incubation time. However, the peak currents remain almost unchanged after incubation for $6 \mathrm{~h}$, indicating that the imprinted cavities in the MIP film are completely occupied by the target anti-IgG.

\section{Influence of $\mathrm{pH}$ on the performance of the MIP biosensor}

Further, the influence of $\mathrm{pH}$ for anti-IgG detection on the performance of the MIP biosensor is studied (Fig. S9 in Supporting Information). As can be seen, the highest peak currents are obtained at $\mathrm{pH}$ 7.4. Therefore, $\mathrm{pH} 7.4$ is chosen as the optimized $\mathrm{pH}$ value for the detection of anti-IgG.

\section{Selectivity, reproducibility and stability of the MIP biosensor}

The selectivity of the MIP biosensor is studied by the detection of anti-IgG, BSA, Glu, L-Tyr, HGB, $\mathrm{Na}^{+}, \mathrm{K}^{+}, \mathrm{Ca}^{2+}$, $\mathrm{Cl}^{-}$and $\mathrm{HCO}_{3}{ }^{-}$at the same concentration $\left(100 \mathrm{ng} \mathrm{mL}^{-1}\right.$ ), and the changes in $I_{\mathrm{pa}}\left(\Delta I_{\mathrm{pa}}\right)$ are presented in Fig. 8A. It shows that the values of $\Delta I_{\mathrm{pa}}$ upon the addition of BSA, Glu, L-Tyr, $\mathrm{HGB}, \mathrm{Na}^{+}, \mathrm{K}^{+}, \mathrm{Ca}^{2+}, \mathrm{Cl}^{-}$and $\mathrm{HCO}_{3}{ }^{-}$are significantly lower than that upon the addition of anti-IgG, suggesting excellent selectivity of the MIP biosensor. The reproducibility is examined by the detection of $1.0 \mathrm{ng} \mathrm{mL}^{-1}$ anti-IgG with five MIP biosensors fabricated under the same conditions. As shown in Fig. 8B, the values of $I_{\mathrm{pa}}$ vary little
Fig. 8 Evaluation of selectivity (A), reproducibility (B) and stability (C) of the MIP biosensor
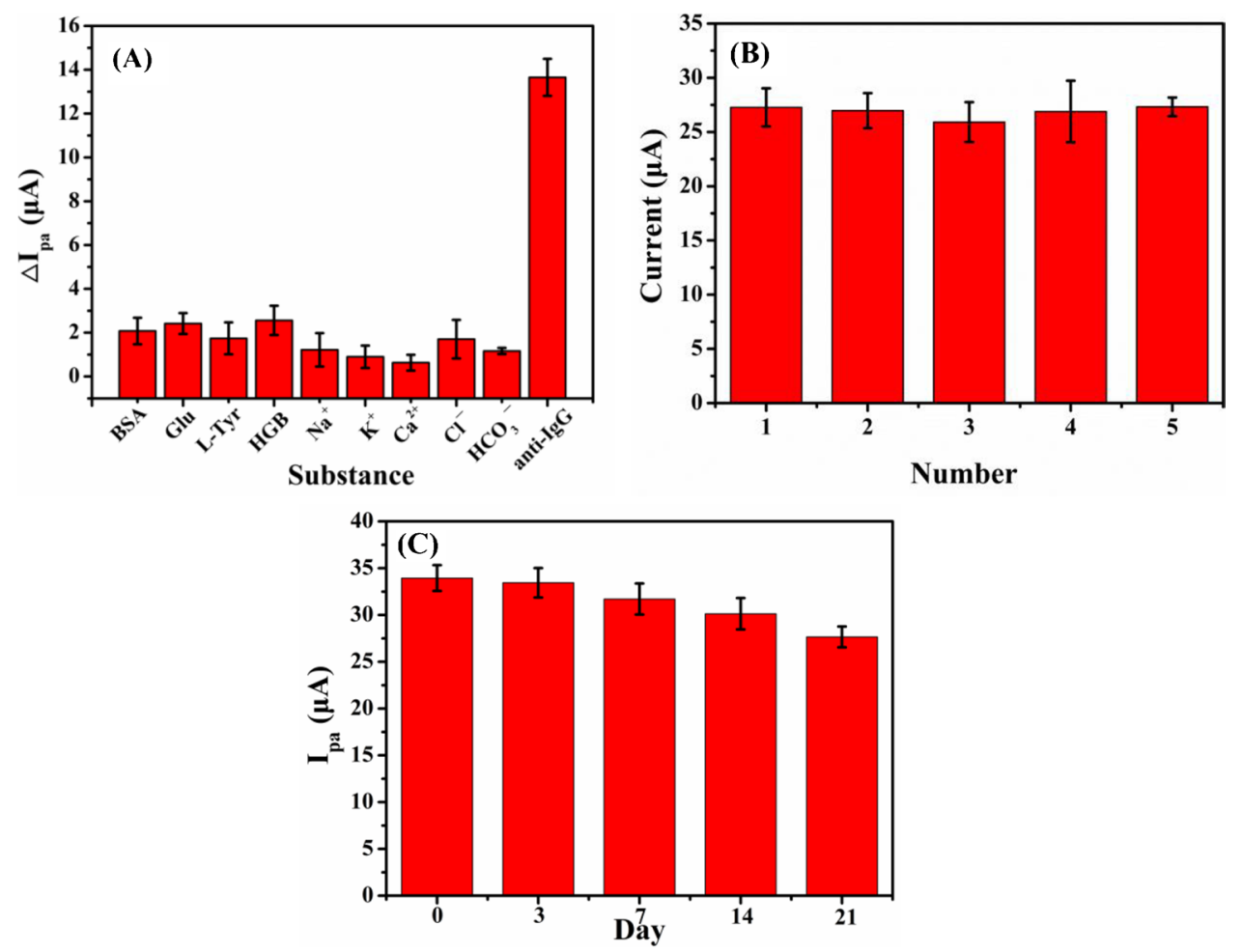
with a relative standard deviation (RSD) of $2.54 \%$, demonstrating excellent reproducibility of the MIP biosensor. In addition, the MIP biosensor is stored at $4{ }^{\circ} \mathrm{C}$ for 3 weeks to evaluate its stability, and the results of the detection of $1.0 \mathrm{ng} \mathrm{mL}^{-1}$ anti-IgG are shown in Fig. 8C. After 2 and 3 weeks, the $I_{\mathrm{pa}}$ can still remain $88.8 \%$ and $81.5 \%$, respectively, of its initial value, suggesting good storage stability of the MIP biosensor.

\section{Detection of anti-IgG in serum sample}

Finally, the practicability of the developed MIP biosensor is assessed by the detection of anti-IgG in serum sample by standard addition method (Table S2 in Supporting Information). The recoveries are in the range between $97.36 \%$ and $100.98 \%$, demonstrating that the detection of anti-IgG in serum sample with the developed MIP biosensor is highly reliable.

\section{Limitations of the MIP biosensor}

Although the developed MIP biosensor can be used for the accurate detection of anti-IgG, it still has two limitations: (1) the probe of $\left[\mathrm{Fe}(\mathrm{CN})_{6}\right]^{3-/ 4-}$ is necessary for the detection of anti-IgG in this work, and the design of label-free MIP biosensors is still needed to further enhance the sensitivity; (2) the MIP biosensor can be further improved to be used for point-of-care sensing, which has significant importance for medical diagnosis [35].

\section{Conclusion}

Accurate detection of protein biomarker plays an important role in the clinic diagnosis. Here, a surface imprinted biosensor based on boronate affinity is fabricated for the electrochemical detection of anti-IgG. The as-fabricated MIP biosensor shows high selectivity, reproducibility and stability when used for the detection of anti-IgG, and the practicability of the biosensor is also confirmed by the detection of anti-IgG in real serum sample. All these findings suggest that the developed MIP biosensor might be a promising and potential candidate for the sensing of anti-IgG, which is of great significance for future design of highly sensitive and selective anti-IgG biosensors.

Supplementary Information The online version contains supplementary material available at https://doi.org/10.1007/s00604-022-05204-w.

Funding The authors are grateful to the financial supports from the Science and Technology Program of Zhejiang Province (LGF22B050008), the Natural Science Foundation for Colleges and Universities in Jiangsu Province (20KJA150005) and the Advanced Catalysis and Green Manufacturing Collaborative Innovation Center (ACGM2016-06-27).

The authors declare no competing interests.

\section{References}

1. Dou BT, Yang JM, Shi K, Yuan R, Xiang Y (2016) DNA-mediated strand displacement facilitates sensitive electronic detection of antibodies in human serums. Biosens Bioelectron 83:156-161

2. Stephenson KE, Wagh K, Korber B, Barouch DH (2020) Vaccines and broadly neutralizing antibodies for HIV-1 prevention. Annu Rev Immunol 38:673-703

3. Somlor S, Brossault L, Grandadam M (2021) Evaluation of VIDAS(R) diagnostic assay prototypes detecting dengue virus NS1 antigen and anti-dengue virus IgM and IgG antibodies. Diagnostics 11:1228

4. Ribeiro JFF, Pereira MIA, Assis LG, Cabral PE, Santos BS, Pereira GAL, Chaves CR, Campos GS, Sardi SI, Pereira G, Fontes A (2019) Quantum dots-based fluoroimmunoassay for anti-Zika virus IgG antibodies detection. J Photochem Photobiol B 194:135-139

5. Hafeez U, Gan HK, Scott AM (2018) Monoclonal antibodies as immunomodulatory therapy against cancer and autoimmune diseases. Curr Opin Pharmacol 41:114-121

6. Kim D, Lee J, Bal J, Chong CK, Lee JH, Park H (2021) Clinical evaluation of an immunochromatographic-based $\mathrm{IgM} / \mathrm{IgG}$ antibody assay (GenBody (TM) COVI040) for detection of antibody seroconversion in patients with SARS-CoV-2 infection. Diagnostics 11:537

7. Hashemi SA, Bahrani S, Mousavi SM, Omidifar N, Behbahan NGG, Arjmand M, Ramakrishna S, Lankarani KB, Moghadami M, Shokripour M, Firoozsani M, Chiang WH (2021) Ultra-precise label-free nanosensor based on integrated graphene with $\mathrm{Au}$ nanostars toward direct detection of IgG antibodies of SARSCoV-2 in blood. J Electroanal Chem 894:115341.

8. Dabrowski M, Lach P, Cieplak M, Kutner W (2018) Nanostructured molecularly imprinted polymers for protein chemosensing. Biosens Bioelectron 102:17-26

9. Chen LX, Xu SF, Li JH (2011) Recent advances in molecular imprinting technology: current status, challenges and highlighted applications. Chem Soc Rev 40:2922-2942

10. Wang YT, Zhou YX, Sokolov J, Rigas B, Levon K, Rafailovich M (2008) A potentiometric protein sensor built with surface molecular imprinting method. Biosens Bioelectron 24:162-166

11. Ouyang J, Liu ZJ, Han YJ, Zeng K, Sheng JP, Deng L, Liu YN (2016) Fabrication of surface potein-imprinted biofuel cell for sensitive self-powered glycoprotein detection. ACS Appl Mater Interfaces 8:35004-35011

12. Xing RR, Ma YY, Wang YJ, Wen YR, Liu Z (2019) Specific recognition of proteins and peptides via controllable oriented surface imprinting of boronate affinity-anchored epitopes. Chem Sci 10:1831-1835

13. Sener G, Ozgur E, Rad AY, Uzun L, Say R, Denizli A (2013) Rapid real-time detection of procalcitonin using a microcontact imprinted surface plasmon resonance biosensor. Analyst 138:6422-6428

14. Islam A, Javed H, Chauhan A, Ahmad I, Rais S (2021) Triethylenetetramine-grafted magnetite graphene oxide-based surfaceimprinted polymer for the adsorption of $\mathrm{Ni}(\mathrm{II})$ in food samples. $\mathrm{J}$ Chem Eng Data 66:456-465

15. Xing RR, Wang SS, Bie ZJ, He H, Liu Z (2017) Preparation of molecularly imprinted polymers specific to glycoproteins, glycans and monosaccharides via boronate affinity controllable-oriented surface imprinting. Nat Protoc 12:964-987

16. Wang SS, Ye J, Bie ZJ, Liu Z (2014) Affinity-tunable specific recognition of glycoproteins via boronate affinity-based controllable oriented surface imprinting. Chem Sci 5:1135-1140

17. Li JJ, Wang Z, Li P, Zong N, Li F (2012) A sensitive non-enzyme sensing platform for glucose based on boronic acid-diol binding. Sens Actuators B 161:832-837 
18. Cai D, Ren L, Zhao HZ, Xu CJ, Zhang L, Yu Y, Wang HZ, Lan YC, Roberts MF, Chuang JH, Naughton MJ, Ren ZF, Chiles TC (2010) A molecular-imprint nanosensor for ultrasensitive detection of proteins. Nat Nanotechnol 5:597-601

19. Beluomini MA, da Silva JL, Sedenho GC, Stradiotto NR (2017) D-mannitol sensor based on molecularly imprinted polymer on electrode modified with reduced graphene oxide decorated with gold nanoparticles. Talanta 165:231-239

20. Wang XD, Dong J, Ming HM, Ai SY (2013) Sensing of glycoprotein via a biomimetic sensor based on molecularly imprinted polymers and graphene-Au nanoparticles. Analyst 138:1219-1225

21. Gan T, Hu SS (2011) Electrochemical sensors based on graphene materials. Microchim Acta 175:1-19

22. Yang J, Tan WS, Chen CX, Tao YX, Qin Y, Kong Y (2017) Nonenzymatic glucose sensing by $\mathrm{CuO}$ nanoparticles decorated nitrogen-doped graphene aerogel. Mater Sci Eng C 78:210-217

23. Cheng JY, Wang XD, Nie TY, Yin L, Wang SM, Zhao YC, Wu HM, Mei H (2020) A novel electrochemical sensing platform for detection of dopamine based on gold nanobipyramid/multi-walled carbon nanotube hybrids. Anal Bioanal Chem 412:2433-2441

24. Banholzer MJ, Harris N, Millstone JE, Schatz GC, Mirkin CA (2010) Abnormally large plasmonic shifts in silica-protected gold triangular nanoprisms. J Phys Chem C 114:7521-7526

25. Zhang J, Sun Y, Wu Q, Gao Y, Zhang H, Bai Y, Song DQ (2014) Preparation of graphene oxide-based surface plasmon resonance biosensor with Au bipyramid nanoparticles as sensitivity enhancer. Colloids Surf B 116:211-218

26. Xu J, Yun QR, Wang CS, Li MM, Cheng S, Ruan QF, Zhu XZ, Kan CX (2020) Gold nanobipyramid-embedded silver-platinum hollow nanostructures for monitoring stepwise reduction and oxidation reactions. Nanoscale 12:23663-23672

27. Ghanbari MH, Khoshroo A, Sobati H, Ganjali MR, RahimiNasrabadi M, Ahmadi F (2019) An electrochemical sensor based on poly (L-Cysteine)@AuNPs@ reduced graphene oxide nanocomposite for determination of levofloxacin. Microchem J 147:198-206
28. Nikoobakht B, El-Sayed MA (2003) Preparation and growth mechanism of gold nanorods (NRs) using seed-mediated growth method. Chem Mater 15:1957-1962

29. Rao WY, Li Q, Wang YZ, Li T, Wu LJ (2015) Comparison of photoluminescence quantum yield of single gold nanobipyramids and gold nanorods. ACS Nano 9:2783-2791

30. Yu J, Zhang YY, Li H, Wan QJ, Li YW, Yang NJ (2018) Electrochemical properties and sensing applications of nanocarbons: a comparative study. Carbon 129:301-309

31. Wang BH, Tan WS, Fu RJ, Mao HH, Kong Y, Qin Y, Tao YX (2017) Hierarchical mesoporous $\mathrm{Co}_{3} \mathrm{O}_{4} / \mathrm{C} @ \mathrm{MoS}_{2}$ core-shell structured materials for electrochemical energy storage with high supercapacitive performance. Synth Met 233:101-110

32. da Silva JL, Buffon E, Beluomini MA, Pradela LA, Araujo DAG, Santos AL, Takeuchi RM, Stradiotto NR (2021) Non-enzymatic lactose molecularly imprinted sensor based on disposable graphite paper electrode. Anal Chim Acta 1143:53-64

33. Forouzanfar S, Alam F, Pala N, Wang CL (2020) Highly sensitive label-free electrochemical aptasensors based on photoresist derived carbon for cancer biomarker detection. Biosens Bioelectron 170:112598.

34. Wang F, Zhu LH, Zhang JD (2014) Electrochemical sensor for levofloxacin based on molecularly imprinted polypyrrole-graphene-gold nanoparticles modified electrode. Sens Actuators B 192:642-647

35. Sarwar M, Rodriguez P, Li CZ (2019) Sweat-based in vitro diagnostics (IVD): from sample collection to point-of-care testing (POCT). J Anal Test 3:80-88

Publisher's note Springer Nature remains neutral with regard to jurisdictional claims in published maps and institutional affiliations. 